with bronchodilators is soundly based. Our findings probably reflect the efficacy of inhaled steroids on airway inflammation. Bronchial hyperresponsiveness, a surrogate for airway inflammation, is improved in these patients. ${ }^{5,6}$ In Haahtela's study of the long-term treatment of mild-to-moderate asthma with inhaled steroids or $\beta_{2}$-agonists, ${ }^{5}$ there was almost complete clinical recovery and normalisation of lung function with confirmed use of inhaled steroids.

In the subgroup of treated patients, bronchial biopsy specimens showed significant reductions in the number of inflammatory cells after budesonide treatment. ${ }^{7}$ Those patients who have a poor response to inhaled steroids are usually those with a more prolonged history before commencement of antiinflammatory treatment. ${ }^{8}$ Our study may therefore provide further evidence for the benefit of early intervention with inhaled steroids in asthma.

We found that the cromone nedocromil sodium had a similar spectrum of activity on symptoms and lung function, but was less potent. This is consistent with the known activity of nedocromil sodium being antiinflammatory, but to a lesser degree than that of inhaled steroids. Within the group of patients responding to nedocromil sodium, as might be anticipated, some patients reported considerable benefit. Whether such patients respond as well as they would to inhaled steroids, thereby establishing nedocromil sodium as a true alternative to inhaled steroids in a subset of patients, is unknown. Unfortunately, there appears to be little likelihood of long-term efficacy studies for this group of compounds.

What is the best first-choice treatment for patients with mild-to-moderate asthma? National guidelines suggest the use of $\beta_{2}$-agonists as the first choice, with early intervention with a low-dose inhaled steroid.
The results of our study suggest that those patients taking short-acting $\beta_{2}$-agonists are following a treatment which does not improve lung function and provides poor symptomatic relief. This indicates a need for large-scale studies of first-use inhaled steroids in mild-to-moderate asthma in primary care

\section{Acknowledgements}

We acknowledge the financial support of the following companies: Astra UK, GlaxoWellcome, Fisons and $3 \mathrm{M}$.

\section{References}

1. Janson C, Chinn S, Jarvis D, et al. Physician-diagnosed asthma and drug utilisation in the European Community Respiratory Health Survey. Eur Resp J 1997; 10: 1795-802. 2. Reid J, Orca S, Penrose A, et al. The diagnosis and initial treatment of asthma in young children in New Zealand and the United Kingdom. N Z Med J 1998; 111: 248-51.

3. Barnes PJ. Current issues for establishing inhaled corticosteroids as the anti-inflammatory agents of choice in asthma. J Allergy Clin Immunol 1998; 101: S427-33. 4. The British Thoracic Society, The National Asthma Campaign, The Royal College of Physicians of London, et al. The British Guidelines on Asthma Management. 1995 Review and Position Statement. Thorax 1997; 52(Suppl 1): S1-21. 5. Haahtela T, Jarvinen M, Kava T et al. Comparison of a $\beta_{2}$-agonist, terbutaline, with an inhaled corticosteroid, budesonide, in newly detected asthma. N Engl J Med 1991; 325: 388-92.

6. Juniper EF, Kline PA, Vanzieleghem MA, et al. Effect of long-term treatment with an inhaled corticosteroid (budesonide) on airway hyperresponsiveness and clinical asthma in nonsteroid-dependent asthmatics. Am Rev Respir Dis 1990; 142: 832-6.

7. Laitinen LA, Laitinen A, Haahtela T. A comparative study of the effects of an inhaled corticosteroid, budesonide, and a $B_{2}$ agonist, terbutaline, on airway inflammation in newly diagnosed asthma: a randomized, double-blind, parallel-group controlled trial. J Allergy Clin Immunol 1992; 90: 32-42.

8. Selroos O, Pietinalho AB, Lofroos AB, et al. Effect of early $v s$ late intervention with inhaled corticosteroids in asthma. Chest 1995; 108: 1228-34.

\title{
Preschool children with asthma: Do their GPs know?
}

M.J.A. Tasche, J.H.J.M. Uijen, B.P. Ponsioen, L.W.A. van Suijlekom-Smit, J.C. de Jongste and J.C. van der Wouden

\begin{abstract}
Objective: To answer the following question: Are children with asthma known to their GP?

Methods: Parents of all 464 children, $1-3$ years of age and registered with five general practices, received a postal questionnaire asking about asthma symptoms of the child, and past and present asthma medication. Thus, children were classified as having no, mild, moderate or severe asthma. The GPs' records were checked for recorded asthma symptoms, medication and asthma-related diagnoses. The presence of these items was compared with asthma severity.
\end{abstract}

Results: Eighty-seven percent of parents responded to the questionnaire (mean age of children 30.1 months). For all classes of severity, $75 \%$ of children with asthma were known to their GP. Although all children with severe asthma were known to their GP, the proportion of asthmatic children known to their GP fell with decreasing severity. Symptoms and medication were recorded more often than asthmarelated diagnoses.

Conclusions: Most preschool children with asthma are known to their GP. The diagnosis is recorded less often than asthma symptoms and medication. 
Table 1: Classification of asthma severity according to questionnaire answers

\author{
No asthma \\ no respiratory symptoms and no medication
}

Mild asthma

dyspnoea at least twice in past 12 months

wheezing 4 to 12 times in past 12 months

present weekly use of bronchodilators for less than 6 weeks

present daily use of deptropine for less than 6 weeks or deptropine use in past 12

months

if doctor ever said to parents their child has asthma

if parents think their child has asthma now

Moderate asthma

wheezing less than12 times in the past 12 months

'yes' to at least two out of the three following questions:

Wheezy or asthmatic condition once or more per week?

Hampered in daily activities (feeding, play, going to school or creche)?

Awakened by coughing or wheezing during night-time?

present use of sodium cromoglycate or ketotifen

present use of deptropine for 6 or more weeks

present daily use of bronchodilators

present weekly or monthly use of bronchodilators for 6 weeks

use of corticosteroids for less than 3 weeks in past 12 months

Severe asthma

all three following questions answered 'yes'. ${ }^{8}$

Wheezy or asthmatic condition once or more per week?

Hampered in daily activities (feeding, play, going to school or creche)?

Awakened by coughing or wheezing during night-time?

use of corticosteroids during 3 or more weeks in past 12 months

present use of corticosteroids

\section{INTRODUCTION}

Speight highlighted the underdiagnosis and undertreatment of childhood asthma more than 15 years ago. ${ }^{1}$ In a general practice audit by Levy and Bell, only one-third of asthmatic children had their illness diagnosed before the age of four years, despite most having presented with respiratory symptoms by this age. ${ }^{2}$ Since then, this subject has been of increasing interest to researchers, clinicians and general practitioners. This is reflected in the publication of various consensus reports during the last few years. ${ }^{3-6}$ We would expect more children with asthma-like symptoms to be known to their GPs.

The prevalence of asthma in 0-3-year-olds is high; rates vary from $5 \%$ to $31 \%$ according to the definition of asthma and methods used for identifying cases. Guidelines for appropriate therapy have been widely

Table 2: Number $(\%)$ of GPs' files $(n=464)$ containing asthma symptoms or diagnoses

$\begin{array}{lrr}\text { Asthma symptoms } & & \\ & & \\ \text { All asthma symptoms } & 163 & (35.1) \\ \text { chest congestion or phlegm } & 74 & (15.9) \\ \text { wheeze } & 63 & (13.9) \\ \text { rhonchi } & 63 & (13.6) \\ \text { nocturnal cough } & 37 & (8.0) \\ \text { dyspnoea } & 35 & (7.5)\end{array}$

Asthma-related diagnoses

All asthma-related diagnoses

acute bronchitis

chronic non-specific respiratory disease

asthma

$(35.1)$

$(15.9)$

(13.6)

(8.0)

(7.5) disseminated and publicised ${ }^{3-6}$ and some authors have argued that this process may improve long-term prognosis. ${ }^{7,8}$

By studying GPs' medical records of children, Neville found that $32 \%$ were potentially asthmatic. ${ }^{9}$ No attempt was made, however, to validate these findings by interviewing parents. Strachan ${ }^{10}$ reviewed general practice records of 369 children at seven years of age: $31 \%$ had some record of wheeze. He compared the records with data from parental questionnaires of 174 of these children, and concluded that parental recall of early episodes is incomplete and biased by the severity and persistence of the symptoms of the child.

In the Netherlands, every patient is registered with a general practitioner who acts as 'gatekeeper' to secondary care. This offers a comprehensive sampling base for asthma research. We compared GPs' medical records of children with parental questionnaires to answer the following question: Are preschool children with asthma known to their GP?

\section{METHODS}

Parents of all 464 preschool children (1-3 years old) in five general practices received a postal questionnaire through their GP. Two weeks later, a reminder was sent to non-responders. The practices (both rural and urban areas; nine general practitioners), which were affiliated with the Department of General Practice of Erasmus University, had no special interest in asthma (no clinics or asthma nurses).

As there is no suitable and well-validated questionnaire for assessing asthma in this age group, ${ }^{11}$ we devised one of our own by adopting validated questions from previously developed questionnaires. ${ }^{12-14}$ Our questionnaire contained items about asthma symptoms (such as wheezing, dyspnoea), past and present asthma medication, and morbidity experienced by the child.

Based on the answers received, the children were classified as having no, mild, moderate or severe asthma (Table 1), according to recurrent airway symptoms and use of specific asthma medication. ${ }^{2-5}$ Peak expiratory flow measurements are not possible in most preschool children. Jones et al. showed that asthma symptoms are closely related to results of lung function tests in children over five years. ${ }^{12}$ We examined general practitioners' records (some handwritten, some computerised, some both) of these children, checking them for asthma symptoms, specific asthma medication and asthma-related diagnoses (asthma, acute bronchitis, chronic nonspecific respiratory disease) since birth. The two people who studied the files were unaware of the answers in the parental questionnaire.

Asthma severity, based on questionnaire answers, was compared to asthma symptoms, specific asthma medication and asthma-like diagnoses found in the general practitioners' records. Data were analysed with SPSS-PC. Differences between responders and nonresponders were tested by means of a $\chi^{2}$ test $(p<0.05)$.

\section{RESULTS}

A total of $404 / 464$ (87\%) parents responded to the questionnaire. Analysis of the non-responders 
showed no differences between responders and nonresponders with respect to the GPs' recorded information on contact frequency and the presence of asthma-like symptoms, diagnoses and medication. Forty percent of the non-responders were from ethnic minorities (Morocco and Turkey) compared with $14 \%$ in the total population $(p<0.01)$.

Of the 404 children for whom questionnaires were completed, 281 (70\%) did not suffer from asthma. According to our criteria, 98 (24\%) were classified as having mild asthma, $17(4 \%)$ as having moderate asthma and $8(2 \%)$ as having severe asthma.

Asthma symptoms were recorded in $35 \%$ of the 464 files of children 1-3 years of age (Table 2). The distribution of these asthma symptoms in the GPs' files showed some overlap between different items. Chest congestion with or without sputum production was recorded most frequently, followed by wheezing and rhonchi.

In nearly $32 \%$ of all records, the general practitioners prescribed specific asthma medication, including deptropine, an anticholinergic drug which is frequently prescribed in the Netherlands, but is uncommon elsewhere. ${ }^{7}$ The prescription frequencies of specific asthma drugs are shown in Table 3. For reasons of comparison with other countries, we present figures with and without deptropine. When deptropine prescriptions were excluded, the prescription of specific asthma medication consequently dropped from $32 \%$ to $11 \%$.

Asthma-related diagnoses were registered by GPs in $20 \%$ of the files (Table 2). Acute bronchitis was recorded most frequently. To answer the main question, we compared questionnaire data with the GPs' records. The data from the records for each degree of asthma severity, found in the parental questionnaire, is shown in Figure 1.

All children with severe asthma were known to their GP (either by diagnosis or asthma medication). The proportion drops with falling levels of severity. Asthma-like diagnoses were recorded in fewer children than both asthma symptoms and medication. For all classes of severity combined, $75 \%$ of children with asthma are known to their GPs.

\section{DISCUSSION}

The return of $87 \%$ completed questionnaires was similar to that of other studies on this subject. ${ }^{10,11} \mathrm{~A}$ substantial percentage $(40 \%)$ of the non-responders were from ethnic minorities, who may have had difficulties understanding the questionnaire.

By focusing on information recorded by GPs, we may have underestimated the number of known asthmatics. If we had asked the GP directly: 'Does this child have asthma?', more cases would probably have been classified as 'known'. We suspect this latter method of data collection would be more liable to bias than checking for information that was actually written down during patient care. ${ }^{15}$

In this study, discrepancies between the two sources of information may partly be explained by the effect of time. As the diagnosis of asthma is seldom made in a single consultation, there may be patients who
Table 3: Number $(\%)$ of GPs' files $(n=464)$ with specific asthma medication

$\begin{array}{lrr}\begin{array}{l}\text { Specific asthma medication } \\ \text { All asthma medication }\end{array} & 148 & (31.9) \\ \quad \text { deptropine } & 137 & (29.5) \\ & & \\ \text { All asthma medication (deptropine excluded) } & 51 & (11.0) \\ \text { B2-Sympaticomimetics } & 34 & (7.3) \\ \text { ketotifen } & 30 & (6.5) \\ \text { ipratropium bromide } & 7 & (1.5) \\ \text { corticosteroids } & 7 & (1.5) \\ \text { sodium cromoglycate } & 5 & (1.1) \\ \quad \text { xanthines } & 3 & (0.6)\end{array}$

are still on their way to being diagnosed by their GP among the children we have labelled as 'asthmatic'. Furthermore, questions regarding the diagnosis of mild asthma in this age group and the consequences of this diagnosis for future respiratory disease are still unsolved. ${ }^{16,17}$ Another aspect of time worth mentioning is reflected in the expectation that many children with airway symptoms will grow out of them, especially in this age group where viral infections may cause asthma-like symptoms. ${ }^{18}$

Of all items recorded by GPs, medication was the best recorded. Recorded asthma medication was mostly deptropine, an oral drug with anticholinergic properties. Use of this drug is in accordance with the previous version of the guidelines for asthma in childhood issued by the Dutch College of General Practitioners. ${ }^{19}$ If deptropine had been unavailable (as in other countries), we assume that other drugs would have been prescribed. Antibiotics were excluded from our search as their prescription for asthma is not advised.

The limited number of practices included in our study means that the conclusions should be generalized with caution. Regarding the affiliation with the Department of General Practice, the chance of selection bias will be small as several hundred practices have contact with the Department for teaching, vocational training and research activities. None of the practices that participated in this study had been involved in any previous study in the field of childhood asthma.

For the practices studied, our results indicate that most children with probable asthma are known to their general practitioners. Our results also indicate that both recorded asthma symptoms and specific asthma medication are more sensitive pointers for detecting children with asthma from GPs' files than specific diagnoses of asthma or asthma-like disorders

\section{References}

1. Speight ANP. Is childhood asthma being underdiagnosed and undertreated? BMJ 1978; 2: 331-2.

2. Levy M, Bell L. General practice audit of asthma in childhood. BMJ 1984; 289: 1115-8.

3. Hargreave FE, Dolovich J, Newhouse MT. The assessment and treatment of asthma: A conference report. J Allergy Clin Immunol 1990; 85: 1098-111.

4. Levison $\mathrm{H}$, et al. Canadian consensus on the treatment of asthma in children. Can Med Assoc J 1991; 145: 1449-55.
Marjolein Tasche

General Practitioner

Hans Uijen

General Practitioner

Ben Ponsioen

General Practitioner

Hans van der Wouden

Research Coordinator

Department of General Practice, Room Fe319, Erasmus University, PO Box 1738, 3000 DR Rotterdam, The Netherlands.

Lisette van SuijlekomSmit

Paediatrician

Johan de Jongste Professor in Paediatric Pulmonology

Department of Paediatrics, Erasmus University, PO Box 1738, 3000 DR Rotterdam, The Netherlands and Sophia Children's Hospital, Rotterdam, The Netherlands.

Correspondence to Dr J.C. van der Wouden

Date received: 08/10/98 Date accepted: 01/02/99

Asthma in Gen Pract 1999; 7(1): 9-12 


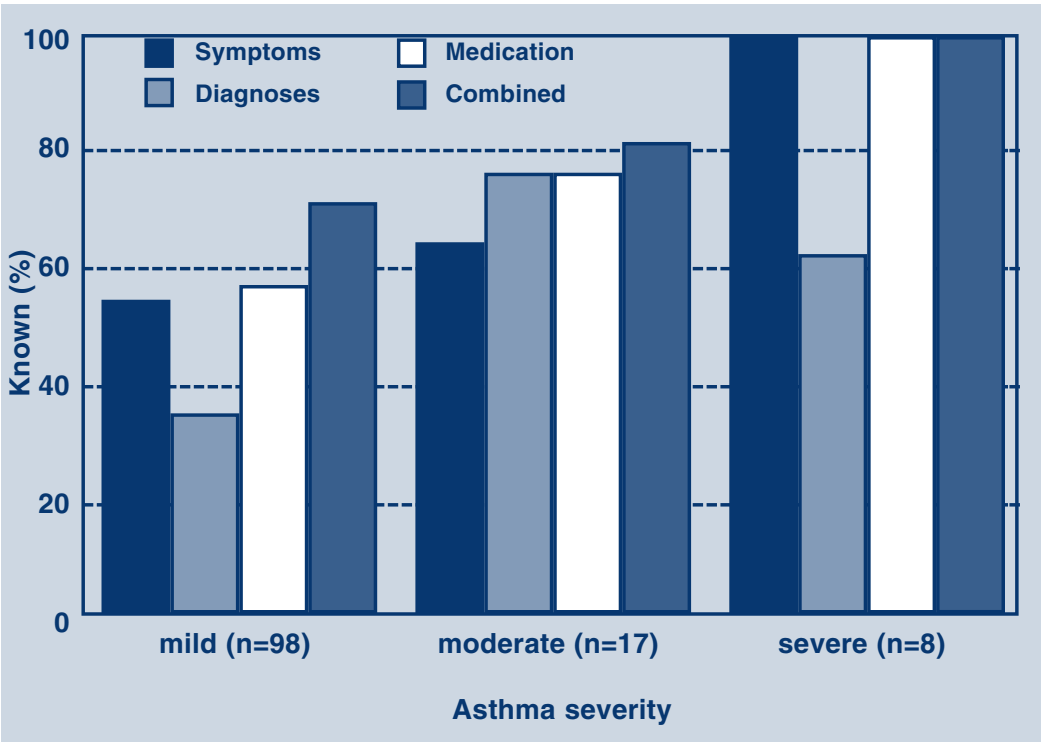

Figure 1: Proportion of asthmatic children known to their GP as indicated by registered symptoms, diagnoses and medication, shown according to degree of asthma severity international paediatric asthma consensus group. Arch Dis Child 1992; 67: $240-8$.

7. Kerrebijn KF. Consensus astma bij kinderen. Ned Tijdschr v Geneeskd 1993; 137: 1239-46.

8. McCarthy TP, Lenny W. Management of asthma in preschool children. Br J Gen Pract 1992; 42: 429-34.

9. Neville RG, Bryce FP, Robertson FM, et al. Diagnosis and treatment of asthma in children: usefulness of a review of medical records. Br J Gen Pract 1992; 42: 501-3.

10. Strachan DP. The prevalence and natural history of wheezing in early childhood. J R Coll Gen Pract 1985; 35: 182-4.

11. Luyt DK, Burton PR, Simpson H. Epidemiological study of wheeze, doctor-diagnosed asthma, and cough in preschool children in Leicestershire. BMJ 1993; 306: 1386-90.

12. Jones KP, Bain DJG, Middleton M, et al. Correlates of asthma morbidity in primary care. BMJ 1992; 304: 361-4.

13. Ferris BG. Epidemiology standardization project. Am Rev Respir Dis 1978; 118(suppl 6): 7-53.

14. Spelman R. Two year follow-up of the management of chronic or recurrent cough in children according to a asthma protocol. Br J Gen Pract 1991; 41: 406-9.

15. Rethans JJ. To what extent do clinical notes by general practitioners reflect actual medical performance? A study using simulated patients. Br J Gen Pract 1994; 44: 153-6.

16. Martinez FD, Wright AL, Taussig LM, et al. Asthma and wheezing in the first six years of life. N Engl J Med 1995; 332: 133-8. 17. Christie GL, Helms PJ, Ross SJ, et al. Outcome for children of parents with atopic asthma and transient childhood wheezy bronchitis. Thorax 1997; 52: 953-7.

18. Martin AJ, McLennan LA, Landau LI, et al. The natural history of childhood asthma to adult life. BMJ 1980; 280: 1397-400.

19. Dirksen WJ, Geyer RMM, de Haan M, et al. NHGstandaard astma bij kinderen. Huisarts Wet 1992; 35: 355-62.

\section{Does implementing COPD guidelines improve patient care and save money in practice?}

R.C.M. Jones and S. Copper

Rupert Jones

General Practitioner

\section{Shirley Copper}

Practice Nurse

The Roborough Surgery,

1 Eastcote Close,

Plymouth, Devon PL6 6HP, UK.

\section{Correspondence to:}

Dr R.C.M. Jones

Date received: 12/10/98

Date accepted: 31/01/99

Asthma in Gen Pract 1999; 7(1): 12-15

\section{ABSTRACT}

Objectives: To identify and assess the management of patients with COPD attending our practice asthma clinic by implementing protocols for the diagnosis and management of COPD, including reversibility testing.

Design and subjects: All patients aged over 39 years attending the asthma clinic at The Roborough Surgery were included. We assessed the implementation of the protocols and analysed prescribing data in those found to have irreversible airflow obstruction.

Results: COPD was found in 35/58 adults $(60 \%)$ over 40 years, of these, $6(17 \%)$ were irreversible. In irreversible patients, less inhaled steroids were prescribed, but this was offset by more anticholinergic prescriptions. The majority had had appropriate diagnostic tests, but the uptake of immunisation was $51 \%$ for influenza and $43 \%$ for pneumococcal infection.

Conclusion: Applying COPD protocols did not reduce prescribing costs, but encouraged optimum patient care in terms of investigations, diagnosis, appropriate treatment and immunisation.

\section{INTRODUCTION}

It has been stated that most patients with COPD have irreversible airway obstruction. ${ }^{1,2}$ These patients often receive expensive, but ineffective, drug treatment. ${ }^{3}$ As the disease progresses and they become more breathless, more treatment is added, with increased prescribing costs. Reversibility testing is useful in excluding chronic asthma from COPD and establishing whether drug therapy is likely to be beneficial. It has been predicted that large savings could be made if reversibility testing is systematically applied to patients with COPD in primary care. $^{3}$

In June 1996, the surgery introduced protocols for the diagnosis and management of COPD agreed by partners and nurses. These include reversibility testing, appropriate investigations, smoking advice, vaccination and treatment review. The protocols were produced in conjunction with British Thoracic Society (BTS) members, but preceded the publication of the BTS guidelines. ${ }^{1}$ They are compatible with the European Respiratory Society (ERS) guidelines. ${ }^{4}$ The primary aim of this audit was to establish how many 